\title{
Spor Tesislerinin Aydınlatmasında Yüksek Enerji Verimli ve LED'li Aydınlatma Araçları
}

\author{
Duygu Yiğit ÜNLÜ ${ }^{1 *}$, Necmettin ŞAHİN ${ }^{2}$ \\ ${ }^{1}$ Aksaray Üniversitesi, Fen Bilimleri Enstitüsü, Makine Mühendisliği ABD, Aksaray \\ ${ }^{2}$ Aksaray Üniversitesi, Makine Mühendisliği Bölümü, Aksaray \\ (ORCID: 0000-0003-2709-1443) (ORCID: 0000-0002-5756-4216)
}

\begin{abstract}
Öz
Spor tesislerinin aydınlatması, aydınlatma uygulamasının özel bir kategorisidir. Oyunun türüne ve seviyesine göre farklı aydınlatma seviyelerine ihtiyaç duyulmaktadır. Sporcuların ve seyircilerin görsel ihtiyaçlarının karşlaması amacıyla spor sahalarında yüksek miktarda enerji tüketilmektedir. Bunun için spor tesislerinin aydınlatılmasında ekonomik ve sürdürülebilir yöntemlere ihtiyaç duyulmaktadır. Ayrıca spor tesislerinde elverişli ve sağlıklı görme koșullarının sağlanması sporcuları hem fizyolojik hem de psikolojik açıdan etkilemektedir. Elverişli ve sağlıklı görme koşullarının sağlanması uygun ve elverişli aydınlatma araçlarının ve standartlarının kullanılması ile gerçekleştirilebilir. Spor tesislerinin aydınlatmasında Türkiye'de EN 12193 Işsı ve Aydınlatma-Spor Aydınlatması standartları kullanılmaktadır. Bu standartlar sporcular, hakemler, seyirciler ve TV iletimi için uygun görsel koşulları sağlamayı amaçlamaktadır. Çalışmada, spor tesislerindeki aydınlatma ve EN 12193 aydınlatma standartları ile ilgili temel bilgiler verilmiştir. Ayrıca çalışmada sürdürülebilir ve ekonomik aydınlatma araçları olan LED'lerin spor tesislerindeki kullanımlarından bahsedilmiştir.
\end{abstract}

Anahtar kelimeler: Aydınlatma, Spor Salonları, LED.

\section{High Energy Efficient and LED Lighting Vehicles in Lighting of Sports Halls}

\begin{abstract}
Lighting of sports fields is a special category of lighting application. Different lighting levels are needed depending on the game type and level. In order to meet the visual needs of athletes and spectators, a high amount of energy is consumed in halls. For this reason, economic and sustainable methods are needed in the lighting of sports fields. In addition, providing suitable and healthy vision conditions in sports fields affects athletes both physiologically and psychologically. Providing favorable and healthy vision conditions can be achieved by using appropriate and favorable lighting tools and standards. In Turkey in the lighting sports fields EN 12193 Light and Lighting-Sports Lighting standards are used. These standards aimed to the provision of appropriate visual conditions for athletes, referees, spectators and TV transmission. In this study, basic information about lighting in sports fields and EN 12193 lighting standards are given. In addition, the use of LEDs, which are sustainable and economical lighting tools, in sports halls is also mentioned.
\end{abstract}

Keywords: Lighting, Gyms, LED.

\section{Giriş}

Spor insanların boş zamanlarını değerlendirdikleri; günlük yaşamda oluşan stresi ve fazla enerjiyi harcadıkları bir ortamın dışında son yıllarda geniş kitleleri peşinden sürükleyen tüm toplumların yakından ilgilendiği önemli alan olmuştur. Spor milletlerarası politikada önemli bir araç ve aynı zamanda endüstriyel bir boyuta ulaşarak ciddi bir ekonomik güç olmuştur. Önceleri toplumun belli bir kesimini ilgilendiren spor ve spor olayları günümüzde toplumun önemli bir kesimini ilgilendirmeye başlamıştır. Bireyler spor ortamında yer alarak kendilerine uygun değişik eylemleri yaparak bedenen ve

"Sorumlu yazar: dyunlu68@gmail.com

Gelis Tarihi: 01.09.2020, Kabul Tarihi: 08.12.2020 
ruhen rahatlarken, günün stresinden de arınmaktadırlar. Spor faaliyetleri her geçen gün dünya çapında yaygınlaşmakta ve popülaritesini artırmaktadır.

Spora katılımın son yıllarda önemli ölçüde artışı, sporun çocuklar, ergenler ve yetişkinler arasında yaygınlaşması ve önemli sosyal işlevleri yerine getirmesi [1], beraberinde çok sayıda ülkede, hem kamu hem de özelde son yirmi yılda spor tesislerinin sayısının giderek artmasına neden olmuştur [2-4].

Spor tesislerinin inşası eski zamanlardan beri ilginç bir alan olmuştur. Çok amaçlı kullanımı ve birçok insanın gereksinimini karşılama zorunluluğu spor tesislerinin inşasında birçok değişkenin göz önünde bulundurulmasını da beraberinde getirmiştir. Bu değişkenlerin kullanıcıların ihtiyaçlarını karşılayacak şekilde bir bütün olarak planlanması gerekmektedir. Günümüzde bir çok yapı yeşil ve sürdürülebilir dizayn standartlarına göre planlanmaktadır. Bu dizayn ekolojik materyaller ve yenilenebilir kaynaklara dayanmaktadır. Ekolojik materyallerin kullanımı ekonomik olmasının yanında çevre kirliliğini de azaltmaktadır. Spor tesislerinin planlanmasında da yeşil ve sürdürülebilir dizayn parametreleri yanında aydınlatmada son derece önemli görülmektedir. Spor tesislerinde ekolojik ve sürdürülebilir bir aydınlatma için gün ışığından yararlanılması hedeflenir [5]. Ayrıca, uygun aydınlatma hem izleyiciler hem de sporcular için bir zorunluluktur. Bu nedenle spor tesislerinin aydınlatması ilginç ve karmaşık bir konu olarak görülmektedir [6]. Uygun bir görsel ortamın oluşturulması, spor tasarımında temel bir gereksinimdir ve yapay aydınlatma sisteminin etkin entegrasyonu, modern bir spor tesisinin standart bir parçası olarak düşünülmektedir [7]. Spor tesislerinin aydınlatmasında gün ışı̆̆ının yetersiz kalması alternatif aydınlatma araçlarına ihtiyacı da beraberinde getirmiştir.

Uzun yıllar spor sahalarının yüzeylerini aydınlatmak için Metal Halide (MH) lambalar kullanılmıştır. Ancak günümüzde daha iyi ışık performansı ve etkinliği ile aynı veya daha fazla ışık akısını sunabilen ve daha az güç tüketimi ile sonuçlanan, böylece işletme ve bakım maliyetlerini azaltan LED 1şıklara doğru bir yönelim olmuştur [7].

Son yıllarda gerek özel gerekse kamusal alanda spor tesislerinin sayısının giderek artması bu mekanların aydınlatma standartlarına uygun olarak aydınlatılmasını beraberinde getirmiştir. Spor tesislerinde standartlara uygun, kaliteli, sürdürülebilir, çevre dostu, ekonomik, sporcular ve izleyiciler için uygun aydınlatmaların sağlanabilmesi için bu konuda yapılacak araştırmalara ihtiyaç bulunmaktadır. Buradan hareketle bu çalışmada spor tesislerinin aydınlatılması ile ilgili çalışmalar incelenmiş ve spor tesislerinin aydınlatılması ile ilgili temel bilgiler sunulmuştur. Çalışmada ayrıca, spor tesislerinin aydınlatılmasında son yıllarda yaygınlaşan LED aydınlatma araçları ile ilgili bilgilere de yer verilmiştir.

\section{Spor Tesislerinde Aydınlatmanın Amacı ve Performans Üzerine Etkileri}

Fiziksel çevrenin ergonomisinde; sağlık, güvenlik ve insanların rahatlığı ön planda tutmalıdır. Ayrıca, gürültü, titreşim, 1s1 ve soğuk, çevreye zarar verebilecek diğer faktörler ve uygun olmayan 1şık faktörü göz önünde bulundurulmalıdır [8]. Spor tesislerinin aydınlatma seviyeleri, homojenlik, renk sıcaklığı ve renk üretimi açısından önemlidir. Sahada iyi görünürlük oyuncuların en iyi performans göstermesine yardımcı olurken, doğru ışık kaynakları seyircilerin ve modern yüksek çözünürlüklü (HD) kameraların aksiyonu yakalamasına yardımcı olur [9]. Bunun için spor ortamında en iyi performansı elde etmek için en uygun çevre koşullarının oluşturulması gerekir [10].

Spor tesisleri; soyunma odaları, saha, antrenman salonları, eğitim sınıfları, park alanları ve spor sahasının etrafı gibi yerleri kapsamaktadır. Tesise bağlı olarak, bir spor tesisinin farklı bölümlerinde farklı 1şık kaynakları kullanılabilir. Kullanılacak mimari aydınlatma aynı zamanda görsel bir estetik oluşturarak ziyaretçilerin ilgisini çekebilir ve sportif etkinlikleri daha karlı hale getirebilir. Buna paralel olarak, spor tesislerinin çevresindeki iyi aydınlatma koşulları, yarışmadan önce ve sonra seyircilerin güvenliğini artırır. Bir başka önemli husus spor tesislerinin enerji tüketimi açısından sürdürülebilir olması gerekir. Tüm bu öğeler büyük ölçüde ışık kaynağı seçimine bağlıdır. Spor tesislerinde geleneksel olarak kullanılan farklı 1şık kaynakları mevcuttur [9].

Spor aydınlatmalarının temel amacı, sporcular ve seyirciler için uygun ve aydınlık bir ortam sağlamaktır. Tasarım parametreleri arasında aydınlatma miktarı, rahatsızlık parlaması, kontrast ve aydınlık bütünlügü sayılabilir [11]. Bir spor tesisindeki aydınlatma sistemi, oyuncular, sporcular, hakemler, seyirciler ve varsa TV çekimleri için iyi görsel koşullar sağlamalıdır. Yeterli aydınlatma koşullarına ulaşmak için, spor etkinlikleri sırasında görsel bilgi algısını optimize etmek, doğru görsel 
performans seviyelerini korumak ve kabul edilebilir bir görsel konfor seviyesi sağlamak gerekir [12]. Spor alanlarında sağlanacak uygun aydınlatma sayesinde sporcuların performansı iyileştirilebilir, rekabet daha dengeli hale getirilebilir ve olası spor yaralanma sayıs1 azaltılabilir [13].

Spor aydınlatmalarının bir başka amacı da, parlak ve eşit şekilde aydınlatılmış oyun alanları sağlamaktır. Sportif performans için ilgili görsel bilgileri toplama yeteneği birçok alanda etkili performans için esastır. Sporda, görsel dikkatin uygun şekilde organize edilmesi, duygusal motor davranıştan önce gelir ve sportif performansı belirler. Bu nokta da performansı etkileyen dişsal faktörlerden birisi de aydınlatmadır. Uygun aydınlatma motor davranışla ilgili daha fazla ipucu elde edilmesini kolaylaştırmaktadır [14].

Işık, organizmanın yaklaşık bir günlük fizyolojik ve biyolojik süreçlerindeki değişimlerini bir başka ifade ile sirkadiyen ritimlerini de önemli ölçüde etkilemektedir [15]. Sirkardiyen ritim bireyde uyku ve uyanıklık döngüsünün en temel belirleyicilerinden birisidir [16]. Işığın, uyku ve uyanıklık döngüsü, melatonin ve diğer hormonların salgılanması, vücut 1sısı ve kalp atımı üzerinde etkilerinden söz edilmektedir [17]. Özellikle sirkardiyen ritim ve melatonin döngüsü, epifiz bezi tarafindan salgılanan bu nörohormon, rahatlama ve uyku bunun yanında dikkat ve uyarılmışlı̆ın azalması gibi önemli süreçlerde yer alır. Melatonin yüksekliği uyku halinin artmasına ve dikkatle ilgili süreçlerin azalmasına neden olur. Öte yandan, melatonin inhibisyonu uyanıklık düzeyini de arttırır. Bu anlamda, başka bir hormon olan kortizol, melatonine antagonistik bir rol oynar ve günlük yaşam için gerekli uyanıklık seviyesini korumaya yardımcı olur [9]. Yüksek seviyeli mavi dalga boyları içeren beyaz LED aydınlatmalar melatonin inhibisyonunu sağlamaktadır [18]. Bunun yanında, dikkat ve uyanıklık gibi duygusal yoğunluğun da artışına neden olur [19]. Buna karşın orta seviyede halojen veya sıcak flüoresan lambalar ise rahatlamaya melatonin salınımına neden olur [9]. Konu ile ilgili yapılan araştırmalarda; 1şığın insan duygusu ve davranışı üzerine etkisi olduğu belirtmekle beraber duygusal etmenlerin ışığa maruz kalmayla da doğrudan ilişkili olduğu belirtmiştir $[18,20]$.

Spor tesislerindeki aydınlatma bireylerin fizyolojilerini etkilediği gibi aynı zamanda psikolojik süreçlerini de etkilemektedir. Özellikle uyarılmışlık ve stres gibi şiddetle ilgili psikolojik özellikler de aydınlatmadan etkilenebilmektedir. Spor karşılaşmalarının öncesinde ve sonrasında sporcuların ve taraftarlarında katıldığı şiddet ve saldırganlık içeren olaylara rastlanabilmektedir [21, 22]. Dinamik LED aydınlatmalar düşük enerji tüketimiyle şiddeti önlemek için iyi bir yöntem olarak gösterilmektedir. LED lambaların seyirciler arasındaki şiddet içerikli davranışları azalttığı belirtilmiştir [9].

Spor tesislerinin aydınlatmasında son yıllarda sporcuların daha iyi performans göstermelerini ve aynı zamanda daha düşük enerji tüketimi sağlayacak aydınlatma araçlarına doğru bir yönelim bulunmaktadır. Bu noktada, açıklanan avantajlarına ek olarak iyi bir görsel konfor sağlayan LED aydınlatma araçlarının spor alanlarındaki kullanımının giderek yaygınlaştığı görülmüştür [23].

\section{Spor Tesislerinin Aydınlatmasında LED Teknolojisi}

Spor tesislerinde, aydınlatma sistemi genellikle metal halide lambalı $(\mathrm{MH})$ projektörler, borulu Floresan lambalı (FL) armatürler ve LED projektörler gibi farklı tipte armatürlerin kullanımı ile karakterize edilen çözümlerden biri ile gerçekleştirilir [24]. Aydınlatma kaynakları son yıllarda maksimum ışıkta 10.000 $\mathrm{cd} / \mathrm{m} 2$ 'den fazlasını üretebilen ışık yayan LED'lere doğru hızla geçmektedir [10]. İlk iki çözüm yaygın olarak kullanılırken LED'li aydınlatmalar yeni kullanılmaya başladıkları için yeterince yaygın değildi. Ancak son yıllarda elektrik yükünün azaltması için alının önlemler çerçevesinde hem yeni kurulan tesislerde hem de mevcut tesislerin aydınlatma sisteminde yapılan yeniliklerde LED kullanımı önerilmektedir $[25,26]$.

LED aydınlatmalar 1şık akısı $(1 \mathrm{~m})$ ve 1şık şiddetindeki (cd) yüksek performans ve düşük güç tüketimi ile çok çeşitli alanlarda kullanılmaktadır [27]. LED'ler belirli koşullar altında elektromanyetik radyasyon yayan elektronik bileşenlerdir. LED'ler her ne kadar tüm dalga boylarında radyasyon yayabilse de aydınlatmadaki kullanımları görünür dalga boylarıyla sınırlıdır. Spor tesislerinde LED'lerin kullanımıyla ilgili temel sorun her zaman yüksek ışı yoğunluğu ve iyi renk oluşturma ihtiyacından doğmuştur. Bu nedenle son zamanlara kadar LED kurulumları iyi bir seçenek olmamıştır [9]. Ancak, beyaz 1şık yayan mavi LED'lerin geliştirilmesi spor tesislerinde LED’lerin kullanımı için önemli bir başlangıç noktası olmuştur [28]. Hızla değişen ve gelişen bir teknoloji olan LED aydınlatma sistemlerinin yeni versiyonlarının uzun ömürlü olması, yüksek enerji verimi sağlaması, toksik olmayışı, dayanıklı ve esnek oluşundan ötürü kullanımı artmıştır [27]. 
Spor salonlarında kullanılan aydınlatma sistemlerinde LED'li armatürlerin kullanımı, MH ve FL aydınlatma armatürlerine kıyasla temel enerji tüketiminin \%32-\%52 oranında azalmasına katk1 sağlamıştır. LED projektörlerin kullanımı genellikle daha az sayıda armatür gerektirir ve diğer çözümlere kıyasla sınırlı bakım maliyeti ile karakterize edilir. Ancak yüksek yatırım maliyeti gerektirebilir. Bu sebepten dolayı yoğun olarak kullanılan, üst düzey yarışma ve müsabakaların gerçekleştirilec ĕgi spor tesislerine LED’li aydınlatma araçlarının kullanılması makul geri ödeme süreleri içeren yüksek yatırım maliyeti ile karakterize edilebilir [12].

Spor tesislerinde LED'li aydınlatma araçlarının kullanımı çeşitli nedenlerle optimal yönetim için önemli bir hedeftir. Bunlar;

- Diğer 1şık kaynaklarına kıyasla yüksek maliyetli olmasına rağmen son zamanlarda uzun ömürleri, düşük güç tüketimleri ve doğru ışık akısı LED'leri gerçek ve karlı bir seçenek haline getirmiştir [29].

- Tekno-ekonomik değerlendirmelerde aydınlatmada LED projektörlerin kullanımı, birincil enerji tüketiminin azaltılmasını sağlamıştır [12].

- LED'lerin kullanım ömürleri üzerinde olumsuz bir etki yaratmadan ış1k akısı ihtiyaçlara bağlı olarak kolayca artırılabilir veya azaltılabilir.

Özetle, LED teknolojisi farklı aydınlatma alanları için farklı renk, ş̧ık akısı ve aydınlatma şiddeti gibi parametreleri sağlayabilir. Bu durum spor tesisleri ve etrafindaki kentsel çevre için daha iyi bir performans sağlar [9]. EN 12193 Teknik Standardına göre listelenen minimum aydınlatma gereksinimlerini karşılayabilecek aydınlatma sistemi yapılandırmaları Tablo 1'de gösterilmiştir [12].

Tablo 1. MH, FL ve LED armatürlerin temel teknik özellikleri

\begin{tabular}{|l|c|c|c|}
\hline \multicolumn{1}{|c|}{ Armatür } & Metal Halide (MH) & Floresan (FL) & LED \\
\hline Lamba türü & & & \\
& & & \\
\hline & 1 & 340 & 20 \\
\hline Lamba sayısı & 428 & 96 & 97 \\
\hline Elektrik giriş gücü (W) & 71 & 80 & 14.2 \\
\hline Optik verimlilik (\%) & \multicolumn{3}{|c|}{} \\
\hline Tek Lamba Özellikleri & 400 & 6.8 & 1.5 \\
\hline Elektriksel nominal güç (W) & 35.0 & 4000 & 4000 \\
\hline Işık akısı (klm) & 5500 & 80 & 80 \\
\hline Renk sıcaklığı (K) & 92 & $0.90^{* *}$ & $0.90^{* * *}$ \\
\hline Renk oluşturma indeksi & $0.83^{*}$ & $0.99^{* *}$ & $1.00^{* * *}$ \\
\hline Lamba ömrü & $0.99^{*}$ & \multicolumn{2}{|c|}{}
\end{tabular}

\section{Spor Aydınlatmalarında Sürdürülebilirlik}

Ülkelerin enerji talebi her geçen yıl artmaktadır. Bu nedenle mevcut enerji kaynaklarının etkin bir şekilde kullanılmasına ihtiyaç vardır. Aydınlatmanın etkin kullanımı sayesinde büyük enerji tasarrufları sağlanabilir [13]. Spor tesislerinde kullanılacak olan etkin ve enerji verimli aydınlatma doğal aydınlatmadır. Spor sahalarında doğal ışığın kullanılması sporcuların performansları ve sporcular için doğal ve sağlıklı bir atmosfer oluşturma açısından önem taşımaktadır. Doğal aydınlatmada yansıtıcı materyallerin kullanılması aydınlatmayı genişletmenin yanında tüketilen enerji miktarının da azaltılmasını sağlamaktadır. Bu nedenle doğal ş̧ı̆̆ın yetersiz olduğu durumlarda ve yapay aydınlatma gereksiniminde enerji verimli aydınlatma sistemlerinin kullanılması gerekmektedir [5].

Spor aydınlatma teçhizatlarının yıl boyunca genellikle müsabaka ya da antrenman saatlerinde çalıştırıldıkları için uzun hizmet ömürleri vardır [30]. Ancak spor aydınlatmalarında elektriğe olan talep son birkaç yılda özellikle televizyonların yüksek görüntü iletimi gereksinimlerini karşılamak amacıyla önemli ölçüde artmıştır. Yarı profesyonel ve profesyonel olmayan sporların yapılması için minimum aydınlık düzeyi (lüx) gereksinimlerinin belirlenmesi enerji tasarruflu spor aydınlatması sorunu olarak belirtilmektedir [27].

Spor alanlarının aydınlatmalarında bilimsel gerçeklere dayalı olarak planlanmamış ve aceleci uygulamalar büyük miktarda enerji kaybına yol açar [31]. Spor tesislerinde enerji verimliliğini artırmaya yönelik müdahalelerde genellikle temel enerji tüketimlerinden birisi olan oyun alanlarının 
aydınlatılması göz önünde bulundurulmalıdır. Aydınlatma için enerji tüketiminin azaltılmasında lambaların kurulum gücünün azaltılması ve armatürlerin daha iyi dağıtılması en akılcı çözümler olarak gösterilmektedir [24]. Bu durumda spor tesislerinin enerji ve ekonomik sürdürülebilirliğini arttırmak için aydınlatma sistemlerinin ve standartlarının detaylı bir şekilde incelenmesi çok önemlidir [32, 33, 34].

\section{Spor Tesislerinin Aydınlatma Standartları}

Spor tesisleri farklı büyüklüklerde ve farklı seyirci kapasitelerine sahip olabilir. Bunun yanında bazı spor tesisleri özel veya herkese açık olabilir. Binlerce seyirciye veya sadece oyunculara hizmet verebilir. Ancak tüm spor tesislerindeki aydınlatma hızla hareket eden hedeflerin ince bir şekilde ayırt edilebilmesini veya bilinen bir pozisyonda sabit bir hedefi görebilmeyi hedeflemektedir. Bir spor tesisinin aydınlatmasının sporcular ve seyirciler için farklı gereksinimleri karşılaması gerekir.

İyi bir spor aydınlatma sisteminin uygun aydınlık düzeyine, parıltı ve kontrastına sahip olması beklenir. Ayrıca 1şık dağılımının düzgün ve parlamanın da kontrol edilebilir düzeyde olması gerekir. Spor tesisinin aydınlatmasında kabul edilen tasarımın hem nitelik hem de nicelik analizi göz önünde bulundurulmalıdır. Nicelik analizi esas olarak enerji verimliliği ve maliyetin azaltılması anlamına gelirken; nitelik analizi daha iyi bir kaliteye sahip olmak için aydınlatma standartlarının iyileştirilmesi ile ilgilidir [13]. Bir spor tesisinde enerji tasarruflu aydınlatma sistemi tasarlanırken aynı zamanda aydınlatma kalitesinin de göz önünde bulundurulması gerekir [6].

Spor aydınlatması için kriterler, ortalama aydınlatma, maksimum - minimum aydınlatma oranı (Maks: Min) ve varyasyon katsayısı (CV) olarak belirtilir [35]. Yılın çoğunda uzun saatler boyunca kullanılan spor alanlarında gerekli aydınlatma seviyesi ve değerleri sağlanmalıdır.

Genellikle masa tenisinde olduğu gibi oyunun hızlı oynandığı, oyun nesnesinin küçük olduğu ve izleme mesafesinin de uzun olduğu durumlar yüksek aydınlatma seviyelerini gerektirmektedir. Futbol gibi düşük hızda oynanan, oyun nesnesinin büyük olduğu ve yakın izleme alanı gerektiren sporlarda da aydınlatma düzeyinin düşük olması istenmektedir. Ayrıca sportif etkinliğin durumu; antrenman, ulusal veya uluslarası maçlar, TV yayınının olup olmaması gibi durumlar göz önünde bulundurularak farklı aydınlatma seviyeleri gerektirmektedir. Bunun yanında farklı spor branşları için de uygun aydınlatma seviyelerini öneren çeşitli aydınlatma kılavuzları ve aydınlatma özellikleri mevcuttur [36].

Spor aydınlatmasında karşılaşılan birçok değişkenliğe rağmen hedefler her yerde aynıdır, bunlar

- Oyuncuların yüksek performans göstermelerini sağlamak,

- Hem mevcut hem de uzaktaki seyircilerin neler olup bittiğini açıkça görebilmelerini sağlamak,

- Sporun hava karardıktan sonra yapılabilmesini sağlamak,

- Hem oyuncular hem de seyirciler için güvenli bir ortam oluşturmaktır.

Spor sahalarında oyunun oynandığı alan "kort" ya da "saha" gerçek alan olarak isimlendirilmektedir. Birde bu alanın etrafını çevreleyen; oyuncuların ısındığı, saha görevlilerinin, sağlık ekibinin, güvenlik personelinin ve basın mensuplarının bulunduğu alan yer almaktadır. Bu alana güvenli alan denilmektedir [38]. Gerek gerçek oyun alanı ve gerekse oyun alanının etrafını çevreleyen güvenli alan farklı spor branşları için farklı standartları yansıtmaktadır. Oyun esnasında aydınlatılacak alan gerçek oyun alanı ve bu alanı çevreleyen güvenli alanı içermektedir.

Spor tesislerinin aydınlatılmasında esas teknik standart EN 12193'tür. Bu standartta çeşitli aydınlatma parametreleri özellikle yatay ve dikey aydınlatmalar için sürdürülebilir aydınlatma (E) ve aydınlatma düzgünlüğü $(\mathrm{U})$ için minimum sınır değerler belirtilmiştir. Sınır değerler uygulanan oyun seviyesine (antrenman, ulusal yarışmalar, uluslararası yarışmalar) göre değişmektedir [39].

Spor tesisinin kapasitesine bağlı olarak, farklı oyun seviyelerinin çeşitli ihtiyaçları ve farklı izleme mesafeleri dikkate alınarak üç aydınlatma sınıfı (AS) tanımlanmıştır [36];

Aydınlatma sınıfı I (Uluslararası Yarışmalar): Yüksek seyirci kapasitesine ve geniş görüş açısına sahip, ulusal ve uluslararası maçları içermektedir.

Aydınlatma sınıfı II (Ulusal Yarışmalar): Orta seyirci kapasitesine ve orta düzeyde görüş açısına sahip, bölgesel ve yerel maçları içermektedir.

Aydınlatma sınıfi III (Antrenman): Düşük seviyeli maçları, yerel veya küçük kulüp maçlarını, genellikle seyirci içermeyen ya da az sayıda seyircili müsabakaları, genel antrenmanları, okul sporları ve eğlence faaliyetlerini içermektedir. Aydınlık düzeyinin 75 Lux değerinden düşük olmaması gerekir. 
Spor aydınlatmasıyla ilgili bu standartlar; sporcular, hakemler, seyirciler ve televizyon iletimi için en iyi görsel koşulları sağlamak içindir. Spor tesislerinin aydınlatmasında EN 12193 Işık ve Aydınlatma - Spor Aydınlatması Standartı ve bu aydınlatma sınıfının seçimi Tablo 2'de gösterilmiştir [36].

Tablo 2. Aydınlatma sınıfının seçimi

\begin{tabular}{|l|c|c|c|}
\hline \multirow{2}{*}{ Yarışmanın seviyesi } & \multicolumn{3}{|c|}{ Aydınlatma sınıfi } \\
\cline { 2 - 4 } & I & II & III \\
\hline Ulusal ve Uluslarası & $*$ & & \\
\hline Bölgesel & $*$ & $*$ & $*$ \\
\hline Yerel & $*$ & $*$ & $*$ \\
\hline Antrenman & & $*$ & $*$ \\
\hline Rekreasyon/Okul Sporları & & & $*$ \\
\hline
\end{tabular}

\section{Spor Tesislerinde Aydınlatma Gereksinimleri}

Bir spor tesisindeki aydınlatma sisteminin yeterli aydınlatma koşullarını sağlaması spor etkinliklerinin gerçekleşmesi sırasında görsel bilgi algısını optimize etmek, doğru görsel performans seviyelerini korumak ve kabul edilebilir bir görsel konfor seviyesi sağla mak için son derece önemlidir. Spor tesisleri için aydınlatma gereksinimleri de yine EN 12193 Teknik Standardında belirtilmiştir [36].

Aydınlatma gerekliliklerine ek olarak, önemli olan bir başka konu sporcuların günde birkaç saat maruz kaldığı 1şık kaynaklarının fotobiyolojik güvenliğinin ve sağlık etkilerinin doğrulanmasıdır [40, 41, 42]. Spor tesislerinde aydınlığ 1 etkileyen temel parametreler; ortalama yatay sürekli aydınlık, aydınlatma düzgünlüğü, lambaların renk oluşturma indeksi ve rahatsız edici parlama olarak gösterilmektedir [24, 36]. Aydınlatma parametrelerinin minimum gereksinimleri, spor ve aydınlatma sınıfının arasında dikkate alınan kombinasyona göre değişmektedir.

Tablo 3'de farklı aydınlatma sınıflarındaki spor tesislerinin aydınlatılması için öneriler özetlenmektedir. Öneriler çoğunlukla daha çok ilgi duyulan spor branşlarına yönelik olmuştur. Spor branşlarındaki oyun alanlarının geometrik boyutları, yatay ortalama aydınlık değerleri (Em) ve ortalama parıltı düzgünlük değerleri (Uo) minimum değerleri gösterilmiştir [37].

Farklı spor branşları için gereken aydınlatma, kameranın tipine ve hassasiyetine, lens açısına ve oynatma hızına bağlı olarak değişmektedir. Maksimum çekim mesafesine bağlı olarak spor branşları; A, B ve C olmak üzere üç gruba ayrılmıştır. Maksimum çekim mesafesinin farklı spor branşları için seçilen minimum dikey aydınlatma değerleri Şekil 1'de gösterilmiştir [37].

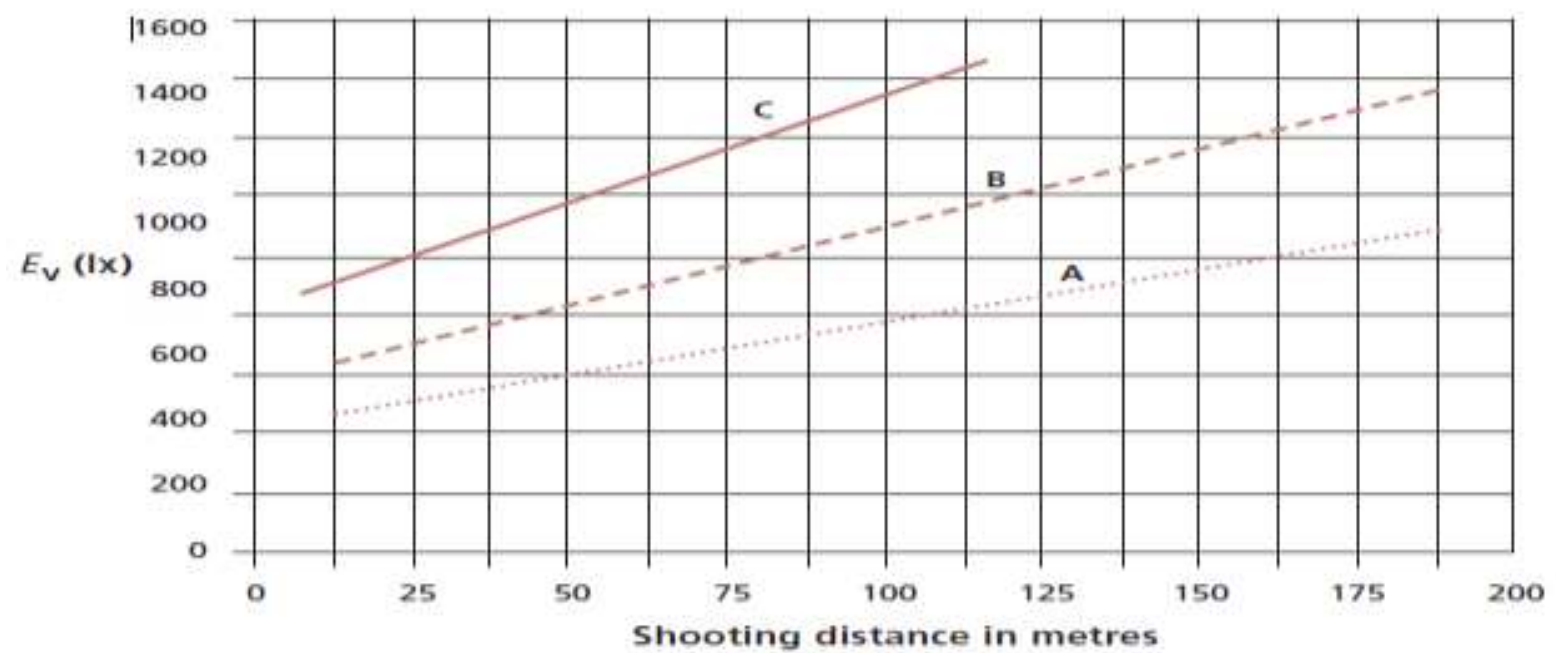

Şekil 1. Maksimum çekim mesafesine bağlı olarak farklı spor branşları için seçilen minimum dikey aydınlatma değerleri 
Tablo 3. Farklı aydınlatma sınıflarına ve farklı sporlara göre kapalı alan spor tesisleri için aydınlatma gereksinimleri

\begin{tabular}{|c|c|c|c|}
\hline \multirow[t]{4}{*}{ Volleyball } & Aydınlatma Sınıf (AS) & Yatay aydınlık $E_{m}(\mathbf{l x})$ & Aydınlatma düzgünlüğğü $\left(\mathrm{U}_{0}\right)$ \\
\hline & I & 750 & 0.70 \\
\hline & II & 500 & 0.70 \\
\hline & III & 200 & 0.50 \\
\hline \multirow[t]{4}{*}{ Tennis } & AS & $\mathbf{E}_{\mathbf{m}}(\mathbf{l} \mathbf{x})$ & $\mathbf{U}_{\mathbf{0}}$ \\
\hline & I & 750 & 0.70 \\
\hline & II & 500 & 0.70 \\
\hline & III & 300 & 0.50 \\
\hline \multirow[t]{4}{*}{ Basketball } & AS & $\mathbf{E}_{\mathbf{m}}(\mathbf{l} \mathbf{x})$ & $\mathbf{U}_{\mathbf{0}}$ \\
\hline & I & 750 & 0.70 \\
\hline & II & 500 & 0.70 \\
\hline & III & 200 & 0.50 \\
\hline \multirow[t]{4}{*}{ Eskrim } & AS & $\mathbf{E}_{\mathbf{m}}(\mathbf{l} \mathbf{x})$ & $\mathbf{U}_{\mathbf{0}}$ \\
\hline & I & 750 & 0.70 \\
\hline & II & 500 & 0.70 \\
\hline & III & 300 & 0.70 \\
\hline \multirow[t]{4}{*}{ Judo } & AS & $\mathbf{E}_{\mathbf{m}}(\mathbf{l} \mathbf{x})$ & $\mathbf{U}_{\mathbf{0}}$ \\
\hline & I & 750 & 0.70 \\
\hline & II & 500 & 0.70 \\
\hline & III & 200 & 0.50 \\
\hline \multirow[t]{4}{*}{ Fitness salonları } & AS & $E_{m}(\mathbf{l x})$ & $\mathbf{U}_{\mathbf{0}}$ \\
\hline & I & 750 & 0.70 \\
\hline & II & 750 & 0.70 \\
\hline & III & 750 & 0.70 \\
\hline \multirow{4}{*}{$\begin{array}{l}\text { Açı ve Kapalı } \\
\text { Yüzme havuzu }\end{array}$} & AS & $E_{m}(\mathbf{l x})$ & $\mathbf{U}_{\mathbf{0}}$ \\
\hline & I & 500 & 0.7 \\
\hline & II & 300 & 0.7 \\
\hline & III & 200 & 0.5 \\
\hline \multirow{4}{*}{$\begin{array}{l}\text { Kapalı Atletizim } \\
\text { sahaları }\end{array}$} & AS & $\mathbf{E}_{\mathbf{m}}(\mathbf{l} \mathbf{x})$ & $\mathbf{U}_{\mathbf{o}}$ \\
\hline & I & 500 & 0.7 \\
\hline & II & 300 & 0.6 \\
\hline & III & 200 & 0.5 \\
\hline \multirow{4}{*}{$\begin{array}{l}\text { Açı Atletizim } \\
\text { sahaları }\end{array}$} & $\mathbf{A S}$ & $E_{m}(\mathbf{l x})$ & $\mathbf{U}_{\mathbf{o}}$ \\
\hline & I & 500 & 0.7 \\
\hline & II & 200 & 0.7 \\
\hline & III & 100 & 0.5 \\
\hline
\end{tabular}

\section{Sonuç ve Öneriler}

$\mathrm{Bu}$ çalışmada spor tesislerinin aydınlatılması, aydınlatma standartları ve spor tesislerinde LED'li aydınlatma araçlarının kullanımı hakkında bilgi verilmiştir. Işığın insan sağlığı ve psikolojisi üzerindeki etkileri göz önüne alındığında spor tesislerinin doğru aydınlatılması sporcuların performanslarını olumlu yönde etkileyecek ve sakatlanma riskini de azaltacaktır. Ayrıca spor tesislerinin görsel konforunu arttıracak ve güvenlik sorunlarının da azalmasına katkı sağlayacaktır.

Spor tesislerinin aydınlatmasında; spor branşına ve sportif etkinliğin niteliğine; uluslarası, ulusal ve antrenman olmak üzere göre üç farklı aydınlatma sınıfı kullanılmaktadır. Türkiye'de spor alanlarının aydınlatılması ile ilgili olarak EN 12193 Işık ve Aydınlatma - Spor Aydınlatması Standartları kullanılmaktadır. Bu standartın amacı spor ortamı için en iyi görsel koşulları sağlamaktır. Spor tesislerinin aydınlatılmasında uygun ve sağlıklı aydınlatma sağlamasının yanında ekonomik olması bakımında da son yıllarda LED'li aydınlatma araçlarının kullanıldığg görülmüştür. LED'li aydınlatma araçları spor tesislerinin aydınlatılmasında sağladığı görsel konfor ve enerji verimli karakteristikleri sayesinde kullanımı giderek yaygınlaşmaktadır. 
Araştırmada spor tesislerinin aydınlatılması ve aydınlatma standartları ile ilgili bilgilere yer verilmiştir. Yapılacak farklı araştırmalarda dış mekân spor sahalarının aydınlatılması ve aydınlatma standartlarına yer verilebilir. Ayrıca spor salonlarının aydınlatmasında sağlıklı, görsel konforu yüksek ve enerji tasarruflu LED armatürler tasarlanabilir.

\section{Yazarların Katkısı}

Yazarlar makaleye eşit oranda katkı sağlamıştır.

\section{Çıkar Çatışması Beyanı}

Yazarlar arasında herhangi bir çıkar çatışması bulunmamaktadır.

\section{Araştırma ve Yayın Etiği Beyanı}

Yapılan çalışmada araştırma ve yayın etiğine uyulmuştur.

\section{Kaynaklar}

[1] Prins R.G., Mohnen S.M., van Lenthe F.J., Brug J., Oenema A. 2012. Are Neighbourhood Social Capital and Availability of Sports Facilities Related to Sports Participation Among Dutch Adolescents? International Journal of Behavioral Nutrition and Physical Activity, 9 (1): 90.

[2] Fried G., Kastel M. 2020. Managing Sport Facilities. Human Kinetics Publishers, USA.

[3] Harger K., Humphreys B.R., Ross A. 2016. Do New Sports Facilities Attract New Businesses? Journal of Sports Economics, 17 (5): 483-500.

[4] Kozma G., Penzes J., Molnar E. 2016. Spatial Development of Sports Facilities in Hungarian Cities of County Rank. Bulletin of Geography Socio Economic Series, 31: 37-44.

[5] Milica I., Miomir V., Dragan K., Vuk M., Nikola C. 2014. Sports Facilities Sustainable Design. In Engineering: Integration of Science and Practice, Proceedings of the International Scientific Conference, 26-28 November, Moscow, Russia, pp: 96.

[6] Salis J.P., Suresh A., Shailesh K.R. 2019. Lighting Design of An Indoor Sports Facility-A Case Study. Second International Conference on Advanced Computational and Communication Paradigms (ICACCP), 25-28 February, India, pp: 1-5.

[7] Georgiou M., Polycarpou A. 2014. Comparison of HPS and LED Technology for Street Lighting Applications. 9th International Conference on Deregulated Electricity Market Issues in SouthEastern Europe (DEMSEE), 25-26 September, Cyprus, pp: 25-26.

[8] Parsons K.C. 2000. Environmental Ergonomics: A Review of Principles, Methods and Models. Applied Ergonomics, 31 (6): 581-594.

[9] Amorim R., Molina-Moreno V., Peña-García A. 2016. Proposal for Sustainable Dynamic Lighting in Sport Facilities to Decrease Violence Among Spectators. Sustainability, 8 (12): 1298.

[10] Tanaka T., Mukai K., Yamauchi M., Kochi M., Ikeda A., Kuzuhara H., Matsushita K., Hironobu G. 2015. A Study on Glare in A Sports Lighting Environment Using Led Lighting and Diffusion Plates. Journal Electrotechnica and Electronica, 50 (5-6): 30-35.

[11] Kayakuş M., Üncü İ.S. 2018. The Visual Display of Illuminance in Indoor Sport Halls with the Developed Software. International Conference on Multidisciplinary Sciences (ICOMUS), 15-16 December, İstanbul, pp: 731-737.

[12] Fantozzi F., Leccese F., Salvadori G., Rocca M., Garofalo M. 2016. LED Lighting for Indoor Sports Facilities: Can Its Use Be Considered as Sustainable Solution from a Techno-Economic Standpoint? Sustainability, 8 (7): 618.

[13] Wan Norshafizan W.M., Mohamad Y.M., Norfishah W., Noor Hafizah A.A., Rosmalini A.K. 2010. Energy Efficient Lighting System Design for Building. International Conference on Intelligent Systems, Modelling and Simulation, 27-29 January, Liverpool, England, pp: 282-286.

[14] Williams A.M., Janelle C.M., Davids K. 2004. Constraints on the Search for Visual Information in Sport. International Journal of Sport and Exercise Psychology, 2 (3): 301-318. 
[15] Tähkämö L., Partonen T., Pesonen A.K. 2019. Systematic Review of Light Exposure Impact on Human Circadian Rhythm. Chronobiology International, 36 (2): 151-170.

[16] Selvi Y., Özdemir P.G., Özdemir O., Aydın A., Beşiroğlu L. 2010. Sağlık Çalışanlarında Vardiyalı Çalışma Sisteminin Sebep Olduğu Genel Ruhsal Belirtiler ve Yaşam Kalitesi Üzerine Etkisi. Düşünen Adam Psikiyatri ve Nörolojik Bilimler Dergisi, 23 (4): 238-243.

[17] Shanahan T.L., Czeisler C.A. 2000. Physiological Effects of Light on the Human Circadian Pacemaker. Seminars in Perinatology, 24 (4): 299-320.

[18] Vandewalle G., Schwartz S., Grandjean D., Wuillaume C., Balteau E., Degueldre C., Maquet P. 2010. Spectral Quality of Light Modulates Emotional Brain Responses in Humans. Proceedings of the National Academy of Sciences, 107 (45): 19549-19554.

[19] Chellappa S.L., Steiner R., Blattner P., Oelhafen P., Götz T., Cajochen C. 2011. Non-Visual Effects of Light on Melatonin, Alertness and Cognitive Performance: Can Blue-Enriched Light Keep Us Alert? Plos One, 6 (1): e16429.

[20] Lee H. 2019. Effects of Light-Emitting Diode (LED) Lighting Color on Human Emotion, Behavior, and Spatial Impression. Michigan State University, ABD.

[21] Stafford A., Alexander K., Fry D. 2013. Playing Through Pain: Children and Young People's Experiences of Physical Aggression and Violence in Sport. Child Abuse Review, 22 (4): 287299.

[22] Kimble N.B., Russo S.A., Bergman B.G., Galindo V.H. 2010. Revealing an Empirical Understanding of Aggression and Violent Behavior in Athletics. Aggression and Violent Behavior, 15 (6): 446-462.

[23] Suresh A., Salis J.P., Shailesh K.R. 2019. Lighting Optimization to Save Energy in an Indoor Sports Facility. https://ieeexplore.ieee.org/stamp/stamp.jsp?tp=\&arnumber=8883019. (Erişim Tarihi: 18.06.2020).

[24] Fantozzi F., Leccese F., Salvadori G., Rocca M., Capranelli I. 2016. Opportunities for Energy Savings with Interventions on the Lighting Systems of Historical Buildings. 16th IEEE International Conference on Environment and Electrical Engineering, 6-8 June, Florence, Italy, pp: 1076-1081.

[25] Abas N., Khan N. 2015. Review of Fossil Fuels and Future Energy Technologies. Journal of Policy, Planning and Futures Studies, 69: 31-49.

[26] Gana C.K., Sapar A.F., Mun Y.C., Chong, K.E. 2013. Techno-Economic Analysis of LED Lighting: A Case Study in Utem's Faculty Building. Procedia Engineering, 53: 208-216.

[27] Polycarpou A., Yiannou I., Christofides N. 2016. Comparison of MH and LED Performance for Sport Lighting Application. Mediterranean Conference on Power Generation, Transmission, Distribution and Energy Conversion (MedPower 2016), 6-9 November, Belgrade, Serbia, pp: 21.

[28] Nakamura S. 2015. Nobel Lecture: Background Story of the Invention of Efficient Blue Ingan Light Emitting Diodes. Reviews of Modern Physics, 87 (4): 1139.

[29] Valentim A.A., Ferreira H.S., Coletto M.A. 2010. Led Lamps: Impact on Consumption and Power Factor. Revista Ciências do Ambiente On-Line, 6 (1): 29-33.

[30] Houser K.W., Royer M.P., Mistrick R.G. 2010. Light Loss Factors for Sports Lighting. Leukos, 6 (3): 183-201.

[31] Yavuz C., Yanıkoğlu E., Güler O. 2010. Determination of Real Energy Saving Potential of Daylight Responsive Systems: A Case Study from Turkey. Light and Engineering, 18 (2): 99105.

[32] Artuso P., Santiangeli A. 2008. Energy Solutions for Sports Facilities. International Journal of Hydrogen Energy, 33 (12): 3182-3187.

[33] Beusker E., Stoy C., Pollalis S.N. 2012. Estimation Model and Benchmarks for Heating Energy Consumption of Schools and Sport Facilities in Germany. Building and Environment, 49: 324335.

[34] Boussabaine A.H. 2001. A Comparative Approach for Modelling the Cost of Energy in Sport Facilities. Facilities, 19: 194-203.

[35] Houser K.W., Wei M., Royer M.P. 2011. Illuminance Uniformity of Outdoor Sports Lighting. Leukos, 7 (4): 221-235. 
[36] European Committee for Standardization 2007. EN 12193: Light and Lighting, Sports Lighting. https://shop.bsigroup.com/en/ProductDetail/?pid=000000000030164245. (Erişim Tarihi: 18.06.2020).

[37] Boyce P., Raynham P. 2009. The SLL Lighting Handbook. Chartered Institution of Building Services Engineers, London.

[38] Sheard R. 2014. Sports Architecture. Taylor \& Francis, London.

[39] Di Pede M., Leccese F., Salvadori G., Di Ciolo E., Piccini S. 2017. On the Vertical Illuminance in Indoor Sport Facilities: Innovative Measurement Procedure to Verify International Standard Requirements in Fencing Halls. IEEE International Conference on Environment and Electrical Engineering and IEEE Industrial and Commercial Power Systems Europe, 6-9 June, Milan, Italy, pp: 1-6.

[40] Fabio B., Chiara B., Ornella L.R., Laura B., Simonetta F. 2015. Non Visual Effects of Light: An Overview and an Italian Experience. Energy Procedia, 78: 723-728.

[41] Ferlazzo F., Piccardi L., Burattini C., Barbalace M., Giannini A.M., Bisegna F. 2014. Effects of New Light Sources on Task Switching and Mental Rotation Performance. Journal of Environmental Psychology, 39: 92-100.

[42] Leccese F., Salvadori G., Casini M., Bertozzi M. 2012. Lighting of Indoor Work Places: Risk Assessment Procedure. WIT Transactions on Information and Communication Technologies, 44: 89-101. 